\title{
A primary care approach to the management of Arthritis
}

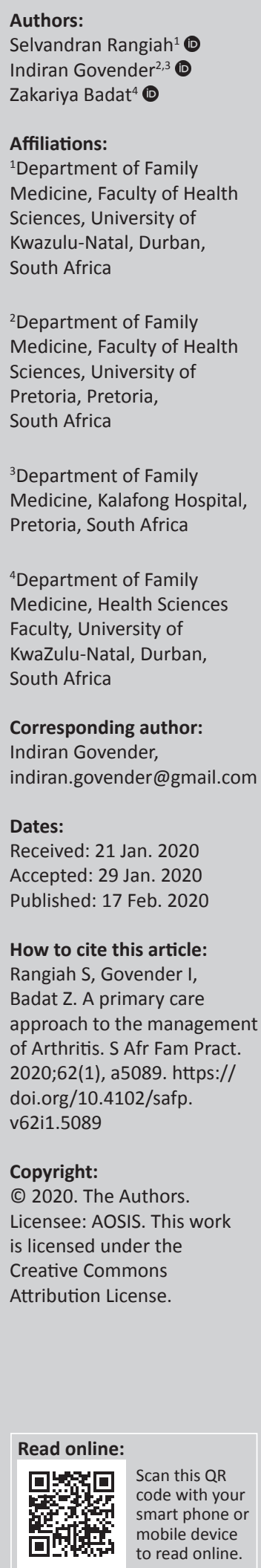

Arthritis is a common condition seen frequently by family practitioners, and there are many types of arthritis. Management of arthritis depends largely on the specific type of arthritis that the patient suffers from. In this article, we will provide the primary care doctor with practical information for managing arthritis, focussing on the management of osteoarthritis and rheumatoid arthritis.

Keywords: osteoarthritis; rheumatoid arthritis; primary care doctor; non-steroidal antiinflammatory drugs.

\section{Introduction}

The term 'arthritis' refers to the swelling of a joint or joints with associated limitation of movement, heat, pain or tenderness, which is caused by inflammation or degeneration of one or more joints. ${ }^{1}$ It is a common cause of disability that impairs one's physical and mental well-being, thus being a major burden on healthcare and economic resources. ${ }^{2}$

In the United States, the prevalence rate of self-reported arthritis is estimated to be about 59.4 million people, ${ }^{3}$ and the condition is a leading cause of major disability in the United Kingdom. ${ }^{4}$

There is a paucity of prevalence data in Africa. In South Africa, osteoarthritis is the most prevalent form of arthritis, with a prevalence rate of $55.1 \%$ in urban settings, and between $29.5 \%$ and $82.7 \%$ in adults over 65 years of age in rural settings. ${ }^{5}$

Arthritis is the pathological feature in over 100 different chronic diseases involving the joints and connective tissues, with the most common forms being osteoarthritis, rheumatoid arthritis (RA) and ankylosing spondylitis. Less common forms of arthritis include systemic lupus erythematosus, scleroderma, psoriatic arthritis and gout. ${ }^{6}$

The three major physiological categories of arthritis include inflammatory (rheumatoid), degenerative (osteoarthritis) and crystal-induced (gout) arthritis. The inflammatory arthritides can be further subdivided into RA (and related disorders) and connective tissue disorders. ${ }^{7}$

Although arthritis may be monoarticular or polyarticular, all types may be monoarticular early in the pathological course. ${ }^{7}$ Therefore, clinical information and imaging studies are crucial in differentiating between the different types of arthritides (Table 1).

When approaching musculoskeletal pain, differentiating between articular and non-articular or diffuse pain narrows the differential, and this is based on history and examination (Figure 1). Articular pain in comparison to non-articular pain is more diffuse and present in both active and passive movements, while non-articular pain is usually localised to the affected structure (e.g. muscle, tendon, bursa, fascia, nerve or bone) and usually limits active rather than passive movements. In non-articular pain joint crepitus, deformity or instability is absent but muscle weakness and wasting may be present. $8,9,10$

\section{Osteoarthritis}

Osteoarthritis is a clinical syndrome of joint pain that is accompanied by varying degrees of functional restriction, reduced quality of life and lack of psychosocial well-being. ${ }^{11,12}$ It is the most common form of degenerative arthritis and one of the leading causes of pain and disability worldwide..$^{1,11}$ 


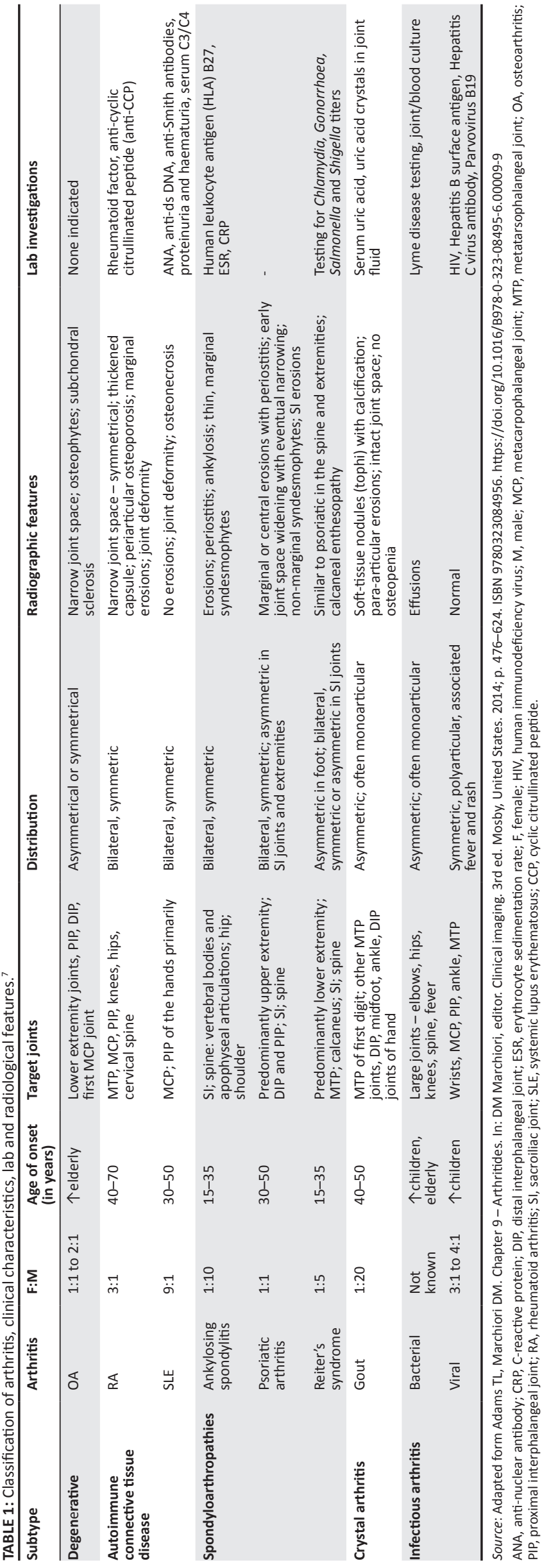

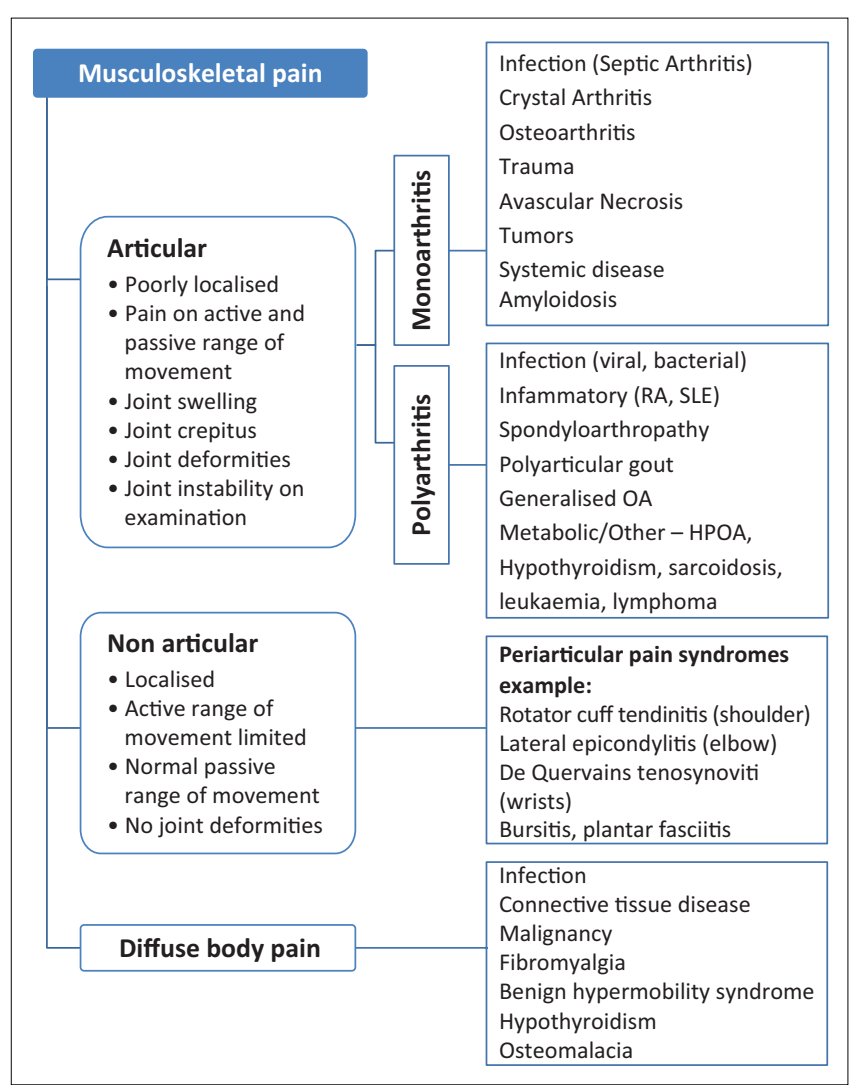

RA, rheumatoid arthritis; OA, osteoarthritis; SLE, systemic lupus erythematosis; HPOA, hypertrophic pulmonary osteoarthropathy.

FIGURE 1: Approach to musculoskeletal pain. ${ }^{8,9,10}$

Damage to the cartilage causes the tissues within the joint to become active, altering its structure, resulting in pain, stiffness and restricted range of movement. Osteophytes develop at the edge of the joint while the synovium thickens and fluid accumulation causes swelling (Figure 2). ${ }^{13}$

\section{Symptoms and signs}

The main symptoms of osteoarthritis are pain and sometimes stiffness in the affected joints. The pain tends to be worse when the joint is moved or at the end of the day. Stiffness occurs at rest and usually improves with activity. ${ }^{15}$

The swelling may be hard and knobbly, which is caused by the growth of extra bone, or it may be soft, which may be caused by the thickening of the synovium and extra fluid inside the joint capsule. ${ }^{16}$

Crepitus is a common sign of osteoarthritis. Muscle wasting around a joint is a late feature.

\section{Diagnosis}

The diagnosis of osteoarthritis is predominantly clinical based on a good history and physical examination. Plain radiological procedures may confirm diagnosis or rule out other medical conditions. ${ }^{17}$ 


\section{Management}

The management of osteoarthritis encompasses both pharmacological and non-pharmacological options involving the patient in decision-making that incorporates adherence and self-management.

Key non-pharmacological interventions include arthritis education, land-based exercise programmes and weight reduction. Optional non-pharmacological interventions include heat therapy, manipulation and massage, transelectrical nerve stimulation (TENS) and water-based exercises. These can be tried according to patient preferences and stopped if found to be ineffective. ${ }^{18}$

The popularity of paracetamol has decreased with new studies questioning the safety profile in comparison to the minimal efficacy it produces. ${ }^{19}$ However, it is reasonable to trial paracetamol at a dose of up to $3 \mathrm{~g} /$ day and discontinue if no response is achieved.

Topical and oral non-steroidal anti-inflammatory drugs (NSAIDS) form the backbone of pharmacological interventions for osteoarthritis. While all NSAIDS share similar efficacy, individual sensitivities may differ. In principle, the lowest dose should be used for the shortest period of time to achieve a clinical response to balance the risk of long-term use.
Comorbid conditions should be factored in when prescribing NSAIDS as they are cardiotoxic, nephrotoxic and cause peptic ulceration. ${ }^{20}$ The conditions for co-prescribing NSAIDS with a PPI and using a selective COX-2 inhibitor are outlined in Figure 3.

Opioids provide marginal efficacy for joint pain but carry a serious risk of abuse, tramadol can be used in certain instances, while other opioids in general should be avoided. Intra-articular steroids are of significant benefit during an acute flare for short-term pain relief. However, repeated injections may result in rapid cartilage loss with no long-term benefit and hence judicious use is warranted..$^{21}$

Figure 4 compares four international guidelines for osteoarthritis management of the knee. The American College of Rheumatology (ACR) published guidelines in 2012 for knee, hand and hip osteoarthritis. ${ }^{18}$ The American Academy of Orthopaedic Surgeons (AAOS) in 2013 laid out guidelines for non-surgical management of osteoarthritis of the knee..2 The Australian guidelines (Royal Australian College of General Practitioners [RACGP]) ${ }^{23}$ in 2018 covered hip and knee OA and the Osteoarthritis Research Society International (OARSI) published its latest guidelines in November 2019. ${ }^{24}$
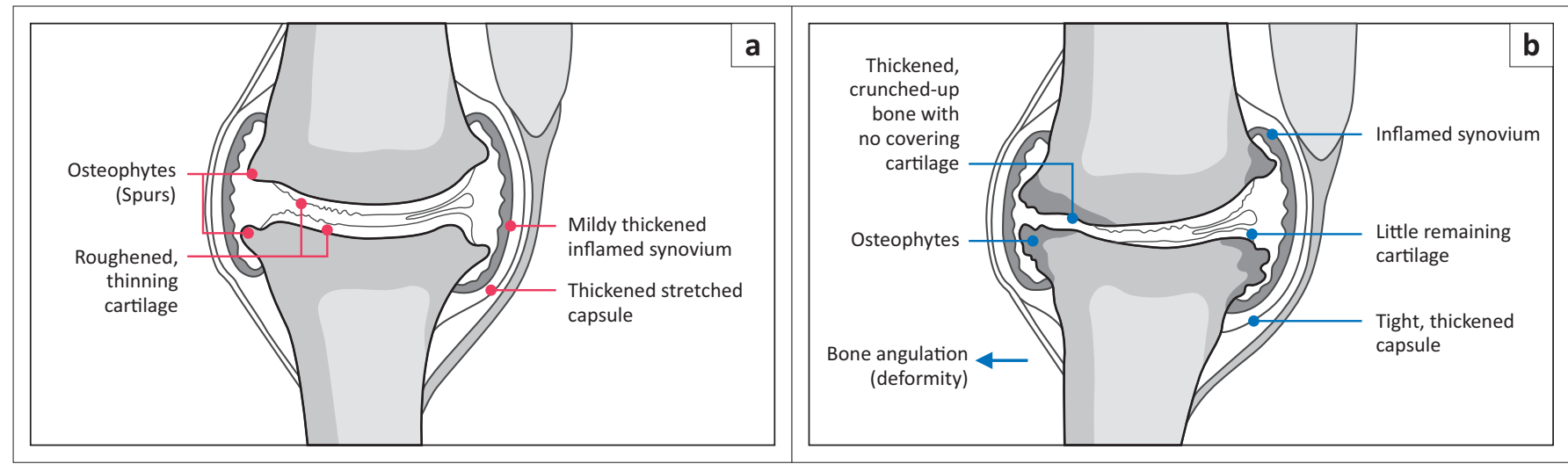

Source: Versus Arthritis. What is Osteorthritis [homepage on the Internet]. [cited 2019 Dec 1]. Available from: https://www.versusarthritis.org/about-arthritis/conditions/osteoarthritis/ FIGURE 2: Osteoarthritis pathological findings. ${ }^{14}$ (a) A joint with mild Osteoarthritis and (b) a joint that has been deformed by severe Osteoarthritis.

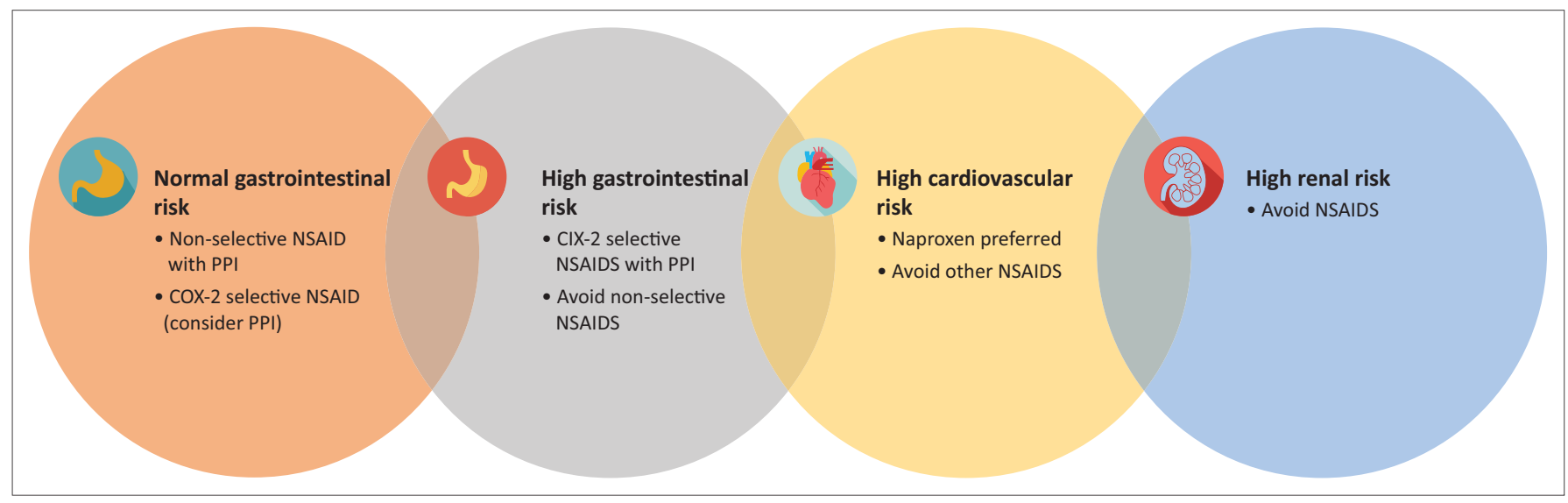

NSAIDS, non-steroidal anti-inflammatory drugs; COX, cyclooxygenase; PPI, proton pump inhibitor.

FIGURE 3: Non-steroidal anti-inflammatory drugs for knee osteoarthritis. 


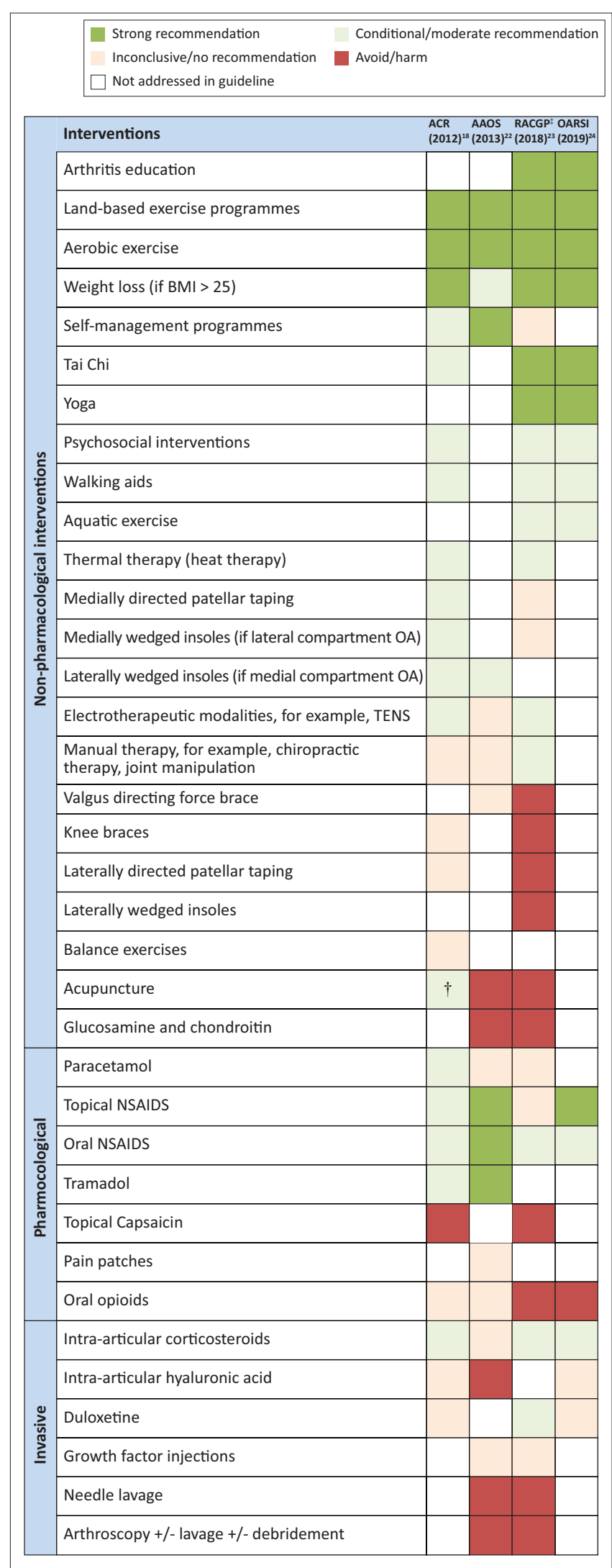

BMI, body mass index; OA, osteoarthritis; ACR, American College of Rheumatology; ACT, The American College of Rheumatology; AAOS, American Academy of Orthopaedic Surgeons; OARSI, Osteoarthritis Research Society International; RACGP, Royal Australian College of General Practitioners.

$\dagger$, Only if a candidate is for total knee replacement but contraindicated or if the patient declines surgery.

\$ RACGP covers both knee and hip osteoarthritis.

FIGURE 4: Summary of international recommendations for knee osteoarthritis management.

\section{Rheumatoid arthritis}

Rheumatoid arthritis is a systemic autoimmune condition, which causes pain, swelling and stiffness of multiple joints of the body. ${ }^{25}$ Tiredness, lack of energy, weight loss, fever, sweating and dry eyes may manifest with systemic involvement. Clinical features are outlined in Table 1.

Autoimmunity and overall systemic and articular inflammation are responsible for the destructive progression of the disease. ${ }^{26}$ Joint capsule instability results as the surrounding joint ligaments become weakened and stretched (Figure 5).

\section{Diagnosis}

Assessment of the patient is based on clinical history and physical examination. The pain of arthritis is the factor that causes patients to frequently seek healthcare. Characteristics such as location, quantity, intensity, nature and the course of pain can assist diagnosis. Other symptoms of arthritis include stiffness, limited motion, fatigue, weakness and swollen joints. The latter can be assessed by inspection or by direct palpation of the joint. A count of the number of swollen joints provides an indication of the amount of inflamed tissue. Use of diaries could prove a useful adjunct to traditional methods of pain assessment (e.g. visual analogue scales) and can incorporate ratings of stiffness, fatigue and mood. ${ }^{27}$

Early diagnosis and initiation of treatment or referral to a physician is key in the prevention of severe disability and the loss of quality of life. ${ }^{27}$

A joint working group of the ACR and the European League against Rheumatism (EULAR) developed updated criteria to assist in making diagnoses earlier (Table 2). ${ }^{26}$ Application of these criteria provides a score of $0-10$, with a score of 6 or more out of 10 being indicative of the presence of definite RA.

General laboratory tests can help determine whether arthritis and its treatment have affected major body systems. A full blood count may reveal the presence of anaemia of chronic disease, a common feature of arthritis. Neutropenia is often associated with severe RA. Liver function tests and viral serology are essential prior to commencement of treatment. ${ }^{26}$

In RA, $80 \%$ of patients will test positive for rheumatoid factor. Positive rheumatoid factor and anti-citrullinated peptide antibody tests are associated with increased disease severity, the development of erosions, extra-articular manifestation and greater disability. Levels of acute phase reactants (e.g. C-reactive protein and erythrocyte sedimentation rate) are used to monitor disease activity. ${ }^{23,25}$ Radiography, or X-rays, is helpful both diagnostically and in monitoring the disease progression.

\section{Management of rheumatoid arthritis}

The management of RA has changed dramatically over the past 30 years. ${ }^{28}$ The fundamental principles revolve around 


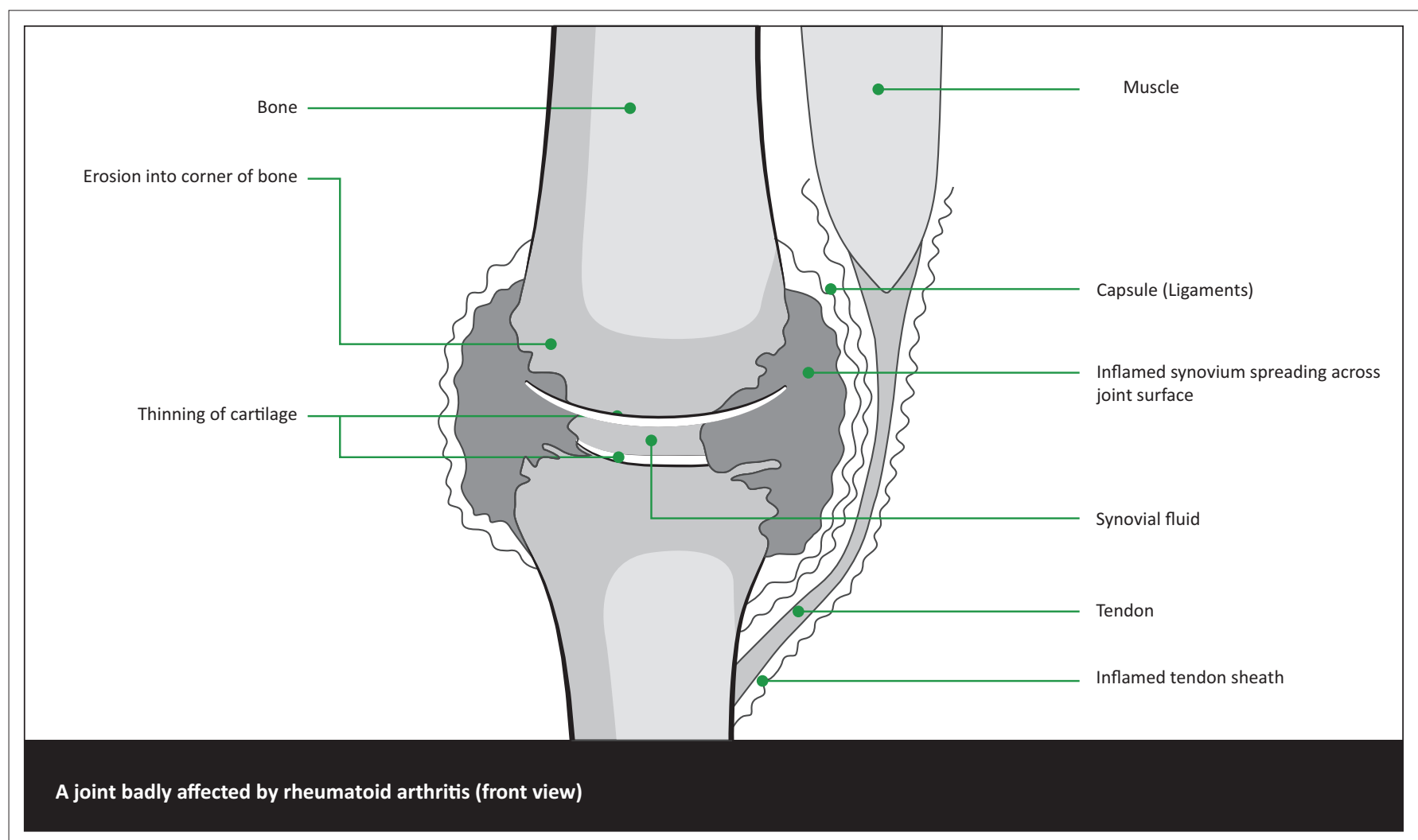

Source: Versus Arthritis. What is Osteorthritis [homepage on the Internet]. [cited 2019 Dec 1]. Available from: https://www.versusarthritis.org/about-arthritis/conditions/osteoarthritis/; Versus Arthritis. What is Osteorthritis [homepage on the Internet]. [cited 2019 Dec 1]. Available from: https://www.versusarthritis.org/about-arthritis/conditions/rheumatoid-arthritis/

FIGURE 5: Pathological features of rheumatoid arthritis. ${ }^{14}$

TABLE 2: The 2010 American College of Rheumatology/European League against Rheumatism classification criteria for rheumatoid arthritis. ${ }^{26}$

\begin{tabular}{ll}
\hline Criteria & Score \\
\hline A. Joint involvement (0-5) & 0 \\
1 large joint & 1 \\
$2-10$ large joints & 2 \\
$1-3$ small joints (with or without involvement of large joints) & 3 \\
$4-10$ small joints (with or without involvement of large joints) & 5
\end{tabular}

\section{B. Serology (0-3)}

Negative RF and negative ACPA 0

Low-positive RF or low-positive ACPA 2

High-positive RF or high-positive ACPA 3

C. Acute-phase reactants (0-1)

Normal CRP and normal ESR

Abnormal CRP or abnormal ESR

D. Duration of symptoms (0-1)

$<6$ weeks

$\geq 6$ weeks

1

Source: Aletaha D, Neogi T, Silman AJ, et al. Rheumatoid arthritis classification criteria: An American College of Rheumatology/European League Against Rheumatism collaborative initiative. Arthritis Rheum. 2010;62(9):2569-2581. https://doi.org/10.1002/art.27584

Note: Add score of $A$ to $D$, a score of $\geq 6 / 10$ needed for classification of RA.

ACR, American College of Rheumatology; CCP, cyclic citrullinated peptide; ACPA, anti-cyclic citrullinated peptide antibody; CRP, C-reactive protein; ESR, erythrocyte sedimentation rate; $\mathrm{RF}$, rheumatoid factor.

disease control within 3-6 months, with the goal being remission or a low disease activity state..$^{28}$

The 2016 update of the EULAR recommendations is based on recent evidence in the area of RA management. ${ }^{29}$ The principles explain the importance of early referral to a rheumatologist (or family physician or internal medicine consultant in settings with restricted access, such as the South African district health system) so that targeted therapy can be initiated based on the principles of monitoring disease activity and shared decision-making.

The recommended target is to reach a state of sustained remission or low disease activity using standardised scoring systems like the disease activity 28 joint score (DAS28). Methotrexate (MTX) is the initial drug of choice if not contraindicated. It is a conventional synthetic diseasemodifying antirheumatic drug (csDMARD). A trial period of 3 to 6 months is the goal before treatment is adjusted according to the degree of improvement.

A second-line drug like another csDMARD (e.g. leflunomide or sulphasalazine) may be added in the presence of poor prognostic factors. Biological drugs (e.g. etanercept) may be added to csDMARDS until remission before the former is weaned off and then the latter.

Biologicals should be co-prescribed with a csDMARD in most cases. It is not advisable to combine two biologicals. Once remission is obtained, first wean off the biological and then the csDMARD.

A multidisciplinary approach through networking with allied health disciplines like physiotherapy, occupational 
TABLE 3: Management of other arthritides.

\begin{tabular}{ll}
\hline Arthritis & Therapeutic Options \\
\hline SLE & $\begin{array}{l}\text { Hydroxychloroquine, glucocorticoids; if they fail, MTX or AZA; biological } \\
\text { - Belimumab }{ }^{30}\end{array}$ \\
$\begin{array}{l}\text { Ankylosing } \\
\text { spondylitis }\end{array}$ & NSAIDS \\
& TNF Inhibitors, for example, infliximab, etanercept, adalimumab \\
& IL17 inhibitors - secukinumab, ixekizumab ${ }^{31}$ \\
Psoriatic & TNF inhibitor biologics \\
arthritis & Oral small molecules - MTX, SSZ, CYC \\
& $\begin{array}{l}\text { IL12/23i - ustekinumab } \\
\text { IL17 inhibitors }\end{array}$ \\
& Smoking cessation ${ }^{32}$ \\
Reiter's & Acute - NSAIDS \\
syndrome & Chronic stage - DMARDS (SSZ, MTX) \\
& Biologics - etanercept, adalimumab \\
Gout & $\begin{array}{l}\text { Acute attack - NSAIDS, systemic steroids if cannot tolerate, or no } \\
\text { response use colchicine }\end{array}$ \\
& $\begin{array}{l}\text { Recurrent attacks (2 or more/year), tophi, urate arthropathy or kidney } \\
\text { failure - urate-lowering therapy with allopurinol (caution - } \\
\text { nephrotoxic) use probenecid }\end{array}$ \\
\hline B3
\end{tabular}

AZA, azathioprine; CYC, cyclosporine; DMARDs, disease-modifying antirheumatic drug; IL, interleukin; MTX, methotrexate; NSAIDs, non steroidal anti-inflammatory drugs; SSZ, salazopyrin; TNF, tumour necrosis factor; SLE, systemic lupus erythematosus.

therapy, podiatry and dietetics is essential to reach goalorientated targets. ${ }^{8}$ Patient education directed at strengthening social and emotional support to enhance self-management of pain and disability as well as adherence to health recommendations is essential. ${ }^{25}$

\section{Summary}

The basic management for some of the other common arthritis is detailed in Table 3.

\section{Conclusion}

While arthritis is common and the differential diagnosis is broad, having a well-rounded approach and holistically managing a patient, including timely referral for the inflammatory forms of arthritis, will result in better patient outcomes, better quality of life and decreased morbidity.

\section{Acknowledgements Competing interests}

The authors declare that they have no financial or personal relationships that may have inappropriately influenced them in writing this article.

\section{Authors' contributions}

All authors contributed equally to this work.

\section{Funding information}

This research received no specific grant from any funding agency in the public, commercial, or not-for-profit sectors.

\section{Data availability statement}

Data sharing is not applicable to this article as no new data were created or analysed in this study.

\section{Disclaimer}

The views and opinions expressed in this article are those of the authors and do not necessarily reflect the official policy or position of any affiliated agency of the authors.

\section{References}

1. National Clinical Guideline Centre. Osteoarthritis: The care and management of osteoarthritis in adults [homepage on the Internet]. 2014 [cited 2019 Dec 2]. Clinical guideline CG177. Available from: https://www.ncbi.nlm.nih.gov/books/ NBK248069/

2. Vina $E R$, Kwoh CK. Epidemiology of osteoarthritis: Literature update. Curr Opin Rheumatol. 2018;30(2):160-167. https://doi.org/10.1097/BOR.0000000000000479

3. Helmick CG, Lawrence RC, Pollard RA, Lloyd E, Heyse SP. Arthritis and other rheumatic conditions: Who is affected now, who will be affected later? Arthritis Rheum. 1995;8(4):203-211. https://doi.org/10.1002/art.1790080403

4. Badley EM, Tennant A. Impact of disablement due to rheumatic disorders in a British population: Estimates of severity and prevalence from the Calderdale Rheumatic Disablement Survey. Ann Rheum Dis. 1993;52(1):6-13. https://doi. org/10.1136/ard.52.1.6

5. Usenbo A, Kramer V, Young T, Musekiwa A. Prevalence of arthritis in Africa: A systematic review and meta-analysis. PLoS One. 2015;10(8):e0133858. https:// doi.org/10.1371/journal.pone.0133858

6. Park J, Mendy A, Vieira ER. Various types of arthritis in the United States: Prevalence and age-related trends from 1999 to 2014. Am J Public Health 2018;108(2):256-258. https://doi.org/10.2105/AJPH.2017.304179

7. Adams TL, Marchiori DM. Chapter 9 - Arthritides. In: DM Marchiori, editor. Clinical imaging. 3rd ed. United States: Mosby, 2014; p. 476-624. ISBN 9780323084956 https://doi.org/10.1016/B978-0-323-08495-6.00009-9

8. Hodkinson B, Van Duuren E, Pettipher C, Kalla AA. South African recommendations for the management of rheumatoid arthritis: An algorithm for the standard of care in 2013-Part 2. S Afr Med J. 2013;103(8):577-585. https://doi.org/10.7196/ SAMJ.7047

9. Pujalte GG, Albano-Aluquin SA. Differential diagnosis of polyarticular arthritis. Am Fam Physician. 2015;92(1):35-41

10. Cush JJ. Approach to articular and musculoskeletal disorders. In: Harrisons principles of internal medicine [homepage on the Internet]. 19th ed. [cited 2019 Dec 2]. Available from: http://www.harrisonsim.com/chapters/CH393_final.pdf

11. Bijlsma WJ, Berenbaum F, Lafeber PJG. Osteoarthritis: An update with relevance for clinical practice. Lancet. 2011;377(9783):2115-2126. https://doi.org/10.1016/ S0140-6736(11)60243-2

12. Allen DA, Golightly YM. Epidemiology of osteoarthritis: State of the evidence. Cur Opin Rheumatol. 2015;27(3):276-283. https://doi.org/10.1097/BOR.0000000 000000161

13. Chen D, Shen J, Zhao W, et al. Osteoarthritis: Toward a comprehensive understanding of pathological mechanism. Bone Res. 2017;5:16044. https://doi.org/10.1038/ boneres.2016.44

14. Versus Arthritis. What is Osteorthritis [homepage on the Internet]. [cited 2019 Dec 1]. Available from: https://www.versusarthritis.org/about-arthritis/conditions/ osteoarthritis/

15. Sellam J, Berenbaum F. The role of synovitis in pathophysiology and clinical symptoms of osteoarthritis. Nat Rev Rheumatol. 2010;6(11):625-635. https://doi. org/10.1038/nrrheum.2010.159

16. Hunter DJ, McDougall JJ, Keefe FJ. The symptoms of osteoarthritis and the genesis of pain. Rheum Dis Clin North Am. 2008;34(3):623-643. https://doi.org/10.1016/j. rdc.2008.05.004

17. Sinusas K. Osteoarthritis: Diagnosis and treatment. Am Fam Physician. 2012;85(1) 49-56. PMID:22230308

18. Hochberg MC, Altman RD, April KT, et al. American College of Rheumatology 2012 recommendations for the use of nonpharmacologic and pharmacologic therapies in osteoarthritis of the hand, hip, and knee. Arthritis Care Res. 2012;64(4): 465-474. https://doi.org/10.1002/acr.21596

19. Roberts E, Delgado Nunes V, Buckner S, et al. Paracetamol: Not as safe as we thought? A systematic literature review of observational studies. Ann Rheum Dis. 2016;75(3):552-559. https://doi.org/10.1136/annrheumdis-2014-206914

20. McAlindon TE, LaValley MP, Harvey WF, et al. Effect of intraarticular triamcinolone vs saline on knee cartilage volume and pain in patients with knee osteoarthritis: A randomized clinical trial. JAMA. 2017;317(19):1967-1975. https://doi.org/ 10.1001/jama.2017.5283

21. Machado GC, Maher CG, Ferreira PH, et al. Efficacy and safety of paracetamol for spinal pain and osteoarthritis: Systematic review and meta-analysis of randomised placebo controlled trials. BMJ. 2015;350:h1225. https://doi.org/10.1136/bmj. h1225 
22. Brown GA. AAOS clinical practice guideline: Treatment of osteoarthritis of the knee: Evidence-based guideline. J Am Acad Orthop Surg. 2013:21(9):577-579. https://doi.org/10.5435/00124635-201309020-00009

23. Royal Australian College of General Practitioners. Guideline for the management of knee and hip osteoarthritis. 2nd ed. East Melbourne, Vic: RACGP; 2018.

24. Bannuru RR, Osani MC, Vaysbrot EE, et al. OARSI guidelines for the non-surgical management of knee, hip, and polyarticular osteoarthritis. Osteoarthritis Cartilage. 2019;27(11):1578-1589. https://doi.org/10.1016/j.joca.2019.06.011

25. Cross M, Smith E, Hoy D, et al. The global burden of rheumatoid arthritis: Estimates from the Global Burden of Disease 2010 study. Ann Rheum Dis. 2014;73(7):1316-1322. https://doi.org/10.1136/annrheumdis-2013-204627

26. Aletaha D, Neogi T, Silman AJ, et al. Rheumatoid arthritis classification criteria: An American College of Rheumatology/European League Against Rheumatism collaborative initiative. Arthritis Rheum. 2010;62(9):2569-2581. https://doi.org/ 10.1002/art.27584

27. Versus Arthritis. What is Osteorthritis [homepage on the Internet]. [cited 2019 Dec 1]. Available from: https://www.versusarthritis.org/about-arthritis/ conditions/rheumatoid-arthritis/

28. Ally M, Hodkinson B. Rheumatoid arthritis. S Afr Fam Pract. 2016;58(2):11-17. https://doi.org/10.4102/safp.v58i2.4446
29. Smolen JS, Landewé R, Bijlsma J, et al. EULAR recommendations for the management of rheumatoid arthritis with synthetic and biological diseasemodifying antirheumatic drugs: 2016 update. Ann Rheum Dis. 2017;76(6): 960-977. https://doi.org/10.1136/annrheumdis-2016-210715

30. Fanouriakis A, Kostopoulou M, Alunno A, et al. 2019 update of the EULAR recommendations for the management of systemic lupus erythematosus. Ann Rheum Dis. 2019;78(6):736-745. https://doi.org/10.1136/annrheumdis-2019215089

31. Ward MM, Deodhar A, Gensler LS, et al. 2019 Update of the American College of Rheumatology/Spondylitis Association of America/Spondyloarthritis Research and Treatment Network recommendations for the treatment of ankylosing spondylitis and nonradiographic axial spondyloarthritis. Arthritis Rheumatol. 2019;71(10):1599-1613. https://doi.org/10.1002/ art.41042

32. Singh JA, Guyatt G, Ogdie A, et al. 2018 American College of Rheumatology/ National Psoriasis Foundation guideline for the treatment of psoriatic arthritis. JPsoriasis Psoriatic Arthritis. 2019;4(1):31-58. https://doi.org/10.1177/247553031 8812244

33. Qaseem A, Harris RP, Forciea MA. Management of acute and recurrent gout: A clinical practice guideline from the American College of Physicians. Ann Intern Med. 2017;166(1):58-68. https://doi.org/10.7326/M16-0570 